\title{
Specific uptake of DHA by the brain from a structured phospholipid, AceDoPC
}

\author{
Nathalie Bernoud-Hubac*, Mayssa Hachem, Amanda Lo Van, Madeleine Picq and Michel Lagarde \\ Univ Lyon, INSA-Lyon, Inserm UMR 1060, Inra UMR 1397 (Laboratoire CarMeN), IMBL, Villeurbanne 69621, France
}

Received 28 November 2016 - Accepted 2 December 2016

\begin{abstract}
Docosahexaenoic acid (DHA; 22:6 $\omega-3$ ) is highly enriched in the brain and is required for proper brain development and function. Its deficiency has been shown to be linked with the emergence of neurological diseases. Dietary $\omega-3$ fatty acid supplements including DHA have been suggested to improve neuronal development and enhance cognitive functions. Findings suggested that DHA is better incorporated into the brain when esterified at the $s n-2$ position of a lysophosphatidylcholine (LysoPC-DHA). AceDoPC is a structured phospholipid or acetyl-LysoPC-DHA. As previously shown for LysoPC-DHA, AceDoPC ${ }^{\infty}$ is a specific and preferred carrier of DHA to the brain. When AceDoPC ${ }^{\circledast}$ was injected to rats that were subjected to an ischemic stroke, it prevents the extension of brain lesions. Regarding the essential role of DHA for cerebral functions, targeting the brain with specific carriers of DHA might provide novel therapeutic approaches to neurodegenerative diseases.
\end{abstract}

Keywords: docosahexaenoic acid / lysophosphatidylcholine / AceDoPC / transport / brain / blood-brain barrier

Résumé - Captage sélectif du DHA par le cerveau à partir d'un phospholipide structuré, I'AceDoPC ${ }^{\circledR}$. L'acide docosahexaénoïque (22:6 $\omega$-3, DHA) est l'acide gras le plus abondant de la sphère cérébro-vasculaire et il est nécessaire au développement cérébral et à l'apprentissage. Par ailleurs, une diminution de la concentration cérébrale en DHA est observée chez les patients souffrant de maladies neurodégénératives. Différentes études réalisées chez l'animal et l'Homme suggèrent qu'un apport nutritionnel adéquat en acides gras polyinsaturés $\omega-3$ et surtout en DHA peut prévenir le déclin cognitif et atténuer les perturbations physiologiques du cerveau associés à l'âge ou aux maladies neurologiques. Le DHA peut être apporté au cerveau sous différentes formes, la lysophosphatidylcholine (LysoPC) possédant du DHA en position sn-2 étant une forme d'apport privilégiée et spécifique de DHA au cerveau. L'AceDoPC ${ }^{\circledR}$ est un phospholipide structuré correspondant à l'acétyl-LysoPCDHA qui est une forme stabilisée de la forme physiologique LysoPC. Nos études montrent que l'AceDoPC ${ }^{\circledast}$ est un transporteur privilégié et spécifique du DHA au cerveau comme la forme physiologique LysoPC. Nous montrons des effets neuro-protecteurs de l'AceDoPC ${ }^{\circledR}$ sur un accident vasculaire cérébral induit chez le rat avec une réduction significative de la taille des lésions. En considérant les rôles essentiels du DHA pour le cerveau, cette nouvelle approche de ciblage cérébral du DHA offre des perspectives prometteuses dans le développement de stratégies préventives et thérapeutiques pour les maladies neurologiques.

Mots clés : acide docosahexaénoïque / lysophosphatidylcholine / AceDoPC / transport / cerveau / barrière hématoencéphalique

\section{Introduction}

Docosahexaenoic acid (DHA or 22:6n-3) is a marine omega-3 polyunsaturated fatty acids ( $\omega-3$ PUFA) of primary importance to the brain where it is highly enriched in neural membranes (O'Brien and Sampson, 1965; Bourre et al., 1993). DHA is required for the

\footnotetext{
*Correspondence: nathalie.bernoud-hubac@insa-lyon.fr
}

development of visual acuity and learning in human and deficiencies in DHA have been associated with learning and cognitive deficits in young animals and humans (Jensen et al., 1996; Makrides et al., 1996). Several studies have also indicated the health benefits of DHA for managing neurodegenerative diseases like Parkinson and Alzheimer diseases (Bousquet et al., 2008; Hashimoto and Hossain, 2011). The precursor of DHA, alpha-linolenic acid (ALA or 18:3n-3), is poorly converted into DHA de novo in mammals, and does not contribute significantly to the brain content of DHA. Therefore, an exogenous supply of 
DHA is necessary and recommended to ensure brain functions, especially during fetal life and early childhood (Rogers et al., 2013; Belkouch et al., 2016; Lo Van et al., 2016).

\section{LysoPC: a physiological privileged form of DHA transport into the brain}

The crossing of blood DHA through the blood-brain barrier (BBB) appears to be crucial for maintaining adequate levels of DHA in the brain. We previously showed that 1-lyso,2docosahexaenoyl-glycerophosphocholine (LysoPC-DHA) is a preferred physiological carrier of DHA to the brain (Thies et al., 1994; Bernoud et al., 1999). DHA, either as nonesterified fatty acid (NEFA) or esterified at the $s n-2$ position of LysoPC, were bound to albumin and injected into the rat to look at the brain accretion. DHA uptake by the brain was around 10-fold more efficient when injected as LysoPC-DHA. This was specific for the brain since this preference was not observed with other organs such as the liver, kidney and heart which even show preference for the non-esterified DHA form (Thies et al., 1994). These results clearly showed that LysoPCDHA is a privileged form of transport of DHA to the brain. We also showed that preference for 1-Lyso-2-DHA-PC by using an in vitro model of $\mathrm{BBB}$ (constituted by brain-capillary endothelial cell and astrocyte co-cultures) compared to nonesterified DHA (Bernoud et al., 1999). The preferential uptake of DHA from LysoPC-DHA has been recently corroborated with the discovery of a protein expressed in the BBB, Mfsd2a allowing specific uptake of LysoPC (Nguyen et al., 2014; Quek et al., 2016).

In another study, ${ }^{13} \mathrm{C}$-labeled DHA esterified in triacylglycerols (TG), the form of DHA in fish oil, was ingested by rats, and the ${ }^{13} \mathrm{C}$-DHA was followed in brain phospholipids and in various blood compartments. It has been shown that DHA accumulated in LysoPC-DHA with only a slight decrease over time (evaluated for $72 \mathrm{~h}$ ), while non-esterified DHA transiently peaked with a return to basal by $12 \mathrm{~h}$ postintake. In brain phospholipids, DHA was found to increase in the main glycerophospholipids (phosphatidylcholine and phosphatidylethanolamine), until $72 \mathrm{~h}$ post-intake. This fits with the fact that LysoPC-DHA, but not non-esterified DHA, is the main carrier of DHA transported by albumin (Brossard et al., 1996).

The same approach was then used in humans with measurement of ${ }^{13} \mathrm{C}$-DHA accumulation in red cells and blood platelets, the former compartment being accepted as an index of the brain DHA accretion. The pattern for the kinetic accumulation of ${ }^{13} \mathrm{C}$-DHA in serum albumin was quite similar to that observed in rats, with a transient peak in the NEFA pool and return to basal by $12 \mathrm{~h}$ post-intake, and accumulation in LysoPC with a slow decrease over time. The incorporation of DHA into platelet phospholipids was rapid and attained a plateau when ${ }^{13} \mathrm{C}$-DHA in the NEFA pool of albumin had returned to basal. A lag phase of $8 \mathrm{~h}$ was observed in red cells followed by a constant rise until 3 days post-intake. This is in good agreement with LysoPC-DHA being the main source of DHA for red cells, whereas platelets take up DHA rather uniquely from the NEFA pool (Brossard et al., 1997).

${ }^{13} \mathrm{C}$-labeled DHA esterified in PC was then ingested by humans. The kinetic of ${ }^{13 \mathrm{C}}$-DHA in phospholipids of red cells was not markedly different from those obtained after ingestion of ${ }^{13} \mathrm{C}$-DHA in TG. This fits again with LysoPC-DHA as the main source of DHA (Lemaitre-Delaunay et al., 1999).

Two position isomers of LysoPC-DHA can be detected in blood plasma, whether DHA is esterified at the $s n-1$ or $s n-2$ position suggesting a migration of the 2-acyl moiety to the $s n-1$ position according to the relative instability of the 2-acyl moiety form (Croset et al., 2000).

Efficient strategies to target the brain with DHA are challenging with high relevance for research and therapeutic applications.

\section{AceDoPC ${ }^{\oplus}$ : a structured phospholipid containing DHA to target the brain}

We have synthesized a structured PC to mimic 2-DHALysoPC and prevent the acyl migration, then keeping the docosahexaenoyl chain at the $s n-2$ physiological position (Polette et al., 1999; Lagarde et al., 2008). This structured PC, named AceDoPC ${ }^{\circledR}$ (1-acetyl,2-docosahexaenoyl-glycerophosphocholine), has the shortest acyl chain at the $s n-1$ position to make AceDoPC ${ }^{\circledR}$ closest to LysoPC-DHA in terms of hydrophobicity. We first blocked the alcohol function at the $s n-1$ position by acetylation by chemical treatment of 1-lyso,2DHA-glycerophosphocholine with acetic anhydride into 1acetyl-2-DHA-PC (Polette et al., 1999). More recently, AceDoPC $^{\circledR}$, has been produced with better yield by a one step-trans-esterification of PC-DHA (Lagarde et al., 2008). A molecular modeling of AceDoPC ${ }^{\circledR}$ and LysoPC-DHA confirmed that they both had similar structure and similar electrostatic and lipophilic potentials (Hachem et al., 2016).

\section{AceDoPC $^{\oplus}$ : an efficient transporter of DHA to the brain}

By combining in vitro and in vivo experiments, we demonstrated that DHA from AceDoPC ${ }^{\circledR}$ was better incorporated into the brain than DHA esterified in $\mathrm{PC}$ or non-esterified DHA, and that this observation was specific to the brain (Hachem et al., 2016).

Using the in vitro model of the BBB constituted by a coculture of brain-capillary endothelial cell and astrocyte, radiolabeled $\left[{ }^{14} \mathrm{C}\right]-\mathrm{DHA}$, either unesterified or esterified in AceDoPC $^{\circledR}$ or in PC-DHA were added to the luminal compartment of the $\mathrm{BBB}$ model. The percentage of radioactivity recovered in the lower medium and in glial cells (that represent the total passage through the $\mathrm{BBB}$ ) from AceDoPC $^{\circledR}$ was higher than for non-esterified DHA and PC$\mathrm{DHA}$, demonstrating that the reconstituted $\mathrm{BBB}$ prefers DHA crossing from AceDoPC ${ }^{\circledR}$. Such a preference for AceDoPC was not observed in brain endothelial cells. Indeed, endothelial cells took up non-esterified DHA and AceDoPC ${ }^{\mathbb{B}}$ similarly, but exported AceDoPC ${ }^{\circledR}$ more efficiently in the lower medium, suggesting a control of the transfer through the endothelial cell monolayer. For both endothelial and glial cells, DHA from AceDoPC $^{B}$ was mainly recovered in phosphatidylcholines and phosphatidylethanolamines (around $70 \%$ in total), with phosphatidylethanolamines being more labeled than phosphatidylcholines, especially in glial cells. $10 \%$ of the radioactivity was present in the neutral lipid fraction (triacylglycerols plus 
non-esterified DHA). AceDoPC was also present as a whole molecule in the lower medium and in cells (less than 15\%). These results suggest that the majority of DHA initially in AceDoPC was released and re-acylated into other phospholipids. $3-10 \%$ DHA was present in LysoPC likely indicating that AceDoPC might have also lost its acetyl moiety.

In vivo studies with 20-day-old rats injected intravenously with either radiolabeled DHA esterified in AceDoPC ${ }^{\mathbb{B}}$ or nonesterified DHA also showed the preferential brain uptake of AceDoPC ${ }^{\circledR}$. This is specific to the brain as it was not observed in the other studied organs. One hour after the injection, the main labeled brain lipid was AceDoPC (75\% of total), further showing that AceDoPC ${ }^{\circledR}$ crossed the BBB in its entire form. With time (1, 24 and $48 \mathrm{~h}$ ), the distribution of radioactivity within the main brain lipid classes showed that $\left[{ }^{14} \mathrm{C}\right]-\mathrm{DHA}$ accumulated in phosphatidylcholines and phosphatidylethanolamines while it decreased from AceDoPC, remaining constant in LysoPC but at a low level (Hachem et al., 2016). The fact that AceDoPC was found in intact form in the brain suggests the existence of a recognition/facilitation system of AceDoPC $^{\circledR}$ by the BBB for its transfer to the brain. As mentioned above, the recent paper by Nguyen et al. (2014) reports the important role of $\mathrm{Mfsd} 2 \mathrm{a}, \mathrm{a} \mathrm{BBB}$ transporter that is constitutively and exclusively expressed by brain endothelial cells, in the uptake of DHA. They demonstrated that Mfsd2a transports DHA across the BBB only in the LysoPC form but not as non-esterified fatty acid. We may then suppose that $\mathrm{Mfsd} 2 \mathrm{a}$ could transport DHA esterified in AceDoPC $^{\circledR}$ as well.

Cerebral topographic distribution of DHA after injection of labeled AceDoPC ${ }^{8}$ showed that the radioactivity was localized mainly in the medulla oblongata, cerebellum, cortex, and hippocampus. This specific distribution is of importance since the hippocampus and cerebral cortex are involved in complex functions including intelligence, memory, and thoughts, and the cerebellum is also specialized in some cognitive functions such as language and attention.

\section{AceDoPC $^{\oplus}$ is neuroprotective in experimental ischemic stroke}

As non-esterified DHA has been shown to induce neuroprotection in rats that underwent a transient cerebral ischemia (Belayev et al., 2009), we compared non-esterified DHA with AceDoPC ${ }^{\circledR}$. Stroke was induced by insertion of a coated monofilament in the external carotid artery of rats. One hour following the induction of stroke, non-esterified DHA or AceDoPC ${ }^{\mathbb{B}}$ solubilized in plasma was intravenously injected. Magnetic resonance imaging of the brain and behavioral tests were realized $24 \mathrm{~h}$ after the injection. The lesion sizes due to the initial stroke were stable in rats receiving the plasma alone as a control, while they decreased in rats receiving nonesterified DHA or AceDoPC ${ }^{\circledR}$, the decrease being higher in rats receiving AceDoPC $C^{\circledR}$. Neuroscores also tended to be improved in the AceDoPC ${ }^{\circledR}$ group (Chauveau et al., 2011). The mechanism of neuroprotection observed remains to be clarified but a reduction of oxidative stress has been suggested. The measurement of brain $\mathrm{F}_{2}$-isoprostanes content, $24 \mathrm{~h}$ after injection of either non-esterified DHA or AceDoPC ${ }^{\circledR}$, showed a decrease of these compounds that was significant when both treatments were pooled.

Altogether, these results showed that AceDoPC ${ }^{\circledR}$ prevent more efficiently deleterious effects of the experimental ischemic stroke than did non-esterified DHA.

\section{Conclusions}

AceDoPC ${ }^{\circledR}$ is a structured phospholipid that is a privileged and specific carrier of DHA to the brain, when compared to other forms of DHA (non-esterified and esterified in PC). The advantage of AceDoPC ${ }^{\circledR}$ over LysoPC-DHA is to maintain DHA at the $s n-2$ position that is the physiological one for PUFA in tissues. AceDoPC ${ }^{\circledR}$ is also neuroprotective in experimental ischemic stroke by preventing the extension of brain lesions and is more efficient than non-esterified DHA to protect the brain. Due to the requirement of DHA to brain functions, this approach to target the brain with this fatty acid would allow new potential preventive and therapeutic strategies for cerebral diseases.

Acknowledgments. The authors thank INSA-Lyon, Inserm, Polaris, ANR "Neuroprotect" 2008, the Ministry of Research and the LISA Carnot institute for their financial support.

\section{References}

Belayev L, Khoutorova L, Atkins KD, Bazan NG. 2009. Robust docosahexaenoic acid-mediated neuroprotection in a rat model of transient, focal cerebral ischemia. Stroke 40: 3121-3126.

Bernoud N, Fenart L, Molière P, et al. 1999. Preferential transfer of 2-docosahexaenoyl-1-lysophosphatidylcholine through an in vitro blood-brain barrier over unesterified docosahexaenoic acid. $J$ Neurochem 72: 338-345.

Belkouch M, Hachem M, Elgot A, et al. 2016. The pleiotropic effects of omega-3 docosahexaenoic acid on the hallmarks of Alzheimer's disease. J Nutr Biochem 38: 1-11.

Bourre JM, Bonneil M, Clément M, et al. 1993. Function of dietary polyunsaturated fatty acids in the nervous system. Prostaglandins Leukot Essent Fatty Acids 48: 5-15.

Bousquet M, Saint-Pierre M, Julien C, Salem N Jr, Cicchetti F, Calon F. 2008. Beneficial effects of dietary omega-3 polyunsaturated fatty acid on toxin-induced neuronal degeneration in an animal model of Parkinson's disease. FASEB J 22: 1213-1225.

Brossard N, Croset M, Lecerf J, et al. 1996. Metabolic fate of an oral tracer dose of [13C]docosahexaenoic acid triglycerides in the rat. Am J Physiol 270: R846- R854.

Brossard N, Croset M, Normand S, et al. 1997. Human plasma albumin transports [13C]docosahexaenoic acid in two lipid forms to blood cells. J Lipid Res 7: 1571-1582.

Chauveau F, Cho TH, Perez M, et al. 2011. Brain-targeting form of docosahexaenoic acid for experimental stroke treatment: MRI evaluation and anti-oxidant impact. Curr Neurovasc Res 8: 95-102.

Croset M, Brossard N, Polette A, Lagarde M. 2000. Characterization of plasma unsaturated lysophosphatidylcholines in human and rat. Biochem J 345(Pt 1): 61-67.

Hachem M, Géloën A, Lo Van A, et al. 2016. Efficient docosahexaenoic acid uptake by the brain from a structured phospholipid. Mol Neurobiol 53: 3205-3215.

Hashimoto M, Hossain S. 2011. Neuroprotective and ameliorative actions of polyunsaturated fatty acids against neuronal diseases: 
beneficial effect of docosahexaenoic acid on cognitive decline in Alzheimer's disease. J Pharmacol Sci 116: 150-162.

Jensen M, Skarsfeldt T, Hoy C. 1996. Correlation between level of (n-3) polyunsaturated fatty acids in brain phospholipids and learning ability in rats. A multiple generation study. Biochim Biophys Acta 1300: 203-209.

Lagarde M, Guichardant M, Picq M, Michaud S, Doutheau S. 2008. Method for preparing acetyl,docosahexaenoyl-glycerophosphocholine and use thereof for delivering polyunsaturated fatty acids. WO 2008/068413.

Lemaitre-Delaunay D, Pachiaudi C, Laville M, Pousin J, Armstrong M, Lagarde M. 1999. Blood compartmental metabolism of docosahexaenoic acid (DHA) in humans after ingestion of a single dose of [(13)C]DHA in phosphatidylcholine. J Lipid Res 40: $1867-1874$.

Lo Van A, Sakayori N, Hachem M, et al. 2016. Mechanisms of DHA transport to the brain and potential therapy to neurodegenerative diseases. Biochimie 130: 163-167.

Makrides M, Neumann M, Gibson R. 1996. Is dietary docosahexaenoic acid essential for term infants? Lipids 31: 115-119.
Nguyen LN, Ma D, Shui G, et al. 2014. Mfsd2a is a transporter for the essential omega-3 fatty acid docosahexaenoic acid. Nature 509: 503-506.

O'Brien J, Sampson E. 1965. Fatty acid and fatty aldehyde composition of the major brain lipids in normal human gray matter, white matter, and myelin. J Lipid Res 6: 545-551.

Polette A, Deshayes C, Chantegrel B, Croset M, Armstrong JM, Lagarde M. 1999. Synthesis of acetyl,docosahexaenoyl-glycerophosphocholine and its characterization using nuclear magnetic resonance. Lipids 34: 1333-1337.

Quek DBY, Nguyen LN, Fanc H, Silver DL. 2016. Structural insights into the transport mechanism of the human sodium-dependent lysophosphatidylcholine transporter Mfsd2a. J Biol Chem 291: 9383-9394.

Rogers L, Valentine C, Keim S. 2013. DHA supplementation: current implications in pregnancy and childhood. Pharmacol Res 70: 13-19.

Thies F, Pillon C, Moliere P, Lagarde M, Lecerf J. 1994. Preferential incorporation of sn-2 lysoPC DHA over unesterified DHA in the young rat brain. Am J Physiol 267: R1273-R1279.

Cite this article as: Bernoud-Hubac N, Hachem M, Lo Van A, Picq M, Lagarde M. 2017. Specific uptake of DHA by the brain from a structured phospholipid, AceDoPC ${ }^{\circ}$. OCL 24(2): D205. 